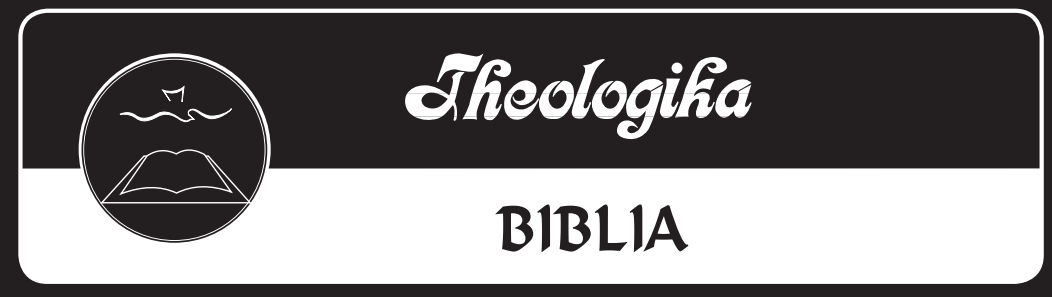

\title{
El ritual de purificación-eliminación: similitudes y diferencias entre los rituales Hebreo e Hitita
}




\section{David Asmat \\ Universidad Peruana Unión Lima-Perú}




\section{RESUMEN}

"El ritual de purificación-eliminación: similitudes y diferencias entre los rituales hebreo e hitita" - La presente investigación analiza las similitudes y el contraste entre las prácticas rituales de purificación-eliminación entre la cultura hebrea e hitita. Sabido es que en el culto hebreo, el concepto de purificación-eliminación es mostrado en forma prominente como parte del ritual del Yom Kipppur (Día de la Expiación) y a través del macho cabrío para Azazel (Lev 16:8, 10, 26), en tanto que entre los hititas, el ritual de mayor paralelo señalado es con el ritual de Puliša (ritual por la plaga). El artículo examina la propuesta que supone que el ritual hebreo se haya originado en el hitita haciendo una evaluación detallada de cada uno de los participantes, elementos y funciones rituales, buscando identificar el rol específico de cada elemento.

Palabras clave: Yom Kippur, Día de la expiación, Azazel, Puliša, ritual por la plaga, purificación, eliminación.

\section{SUMMARY}

"The ritual of purification-elimination: similarities and differences between the Hebrew and Hittite rituals" - This article analyzes the similarities and the contrast between the ritual practices of purificationelimination among the Hebrew and Hittite cultures. It is known that in the Hebrew culture, the concept of purification-elimination appears prominently as part of the ritual of Yom Kipp-pur (Day of Atonenment) and 
through the goat for Azazel (Leviticus 16: 8, 10, 26) while among the Hittites, the parallel ritual is most noted with the ritual of Pulisa (ritual for the plague). The article examines the possibility that the Hebrew ritual was based on the Hittite by making a detailed assessment of each of the participants, elements and ritual functions, and by seeking to identify the specific role of each element in both rituals.

Keywords: Yom Kippur, Expiation day, Azazel, Puliša, ritual for the plague, purification, elimination.

\section{EL RITUAL DE PURIFICACIÓN-ELIMINACIÓN: SIMILITUDES Y DIFERENCIAS ENTRE LOS RITUALES HEBREO E HITITA}

\section{Introducción}

La presente investigación, desarrolla un breve análisis por contraste de las prácticas rituales de purificación-eliminación entre la cultura hebrea e hitita. Dentro del culto hebreo, el concepto de purificacióneliminación forma parte del ritual del Yom Kipppur a través del macho cabrío para Azazel (Lev 16:8, 10, 26), mientras que entre los hititas, el ritual de mayor paralelo señalado ha sido hecho con el ritual de Puliša (ritual por la plaga). ${ }^{1}$ El paralelo se ha resaltado con demasía,

${ }^{1}$ Véase, William W. Hallo and K. Lawson Younger, The Context of Scripture: Canonical Compositions from the Biblical World, vol. 1 (Leiden, Boston: Brill, 
confiriendo al ritual hebreo como originado en las prácticas hititas. Por lo cual, se hará una evaluación de sus participantes, elementos y sus funciones rituales, procurando identificar su rol específico. Asimismo, cada práctica será evaluada bajo consideración de su propia literatura y cultura, permitiéndonos conocer el trasfondo de su práctica y pensamiento, para luego contrastar sus informaciones.

\section{El problema subyacente}

Bremmer ha sugerido que el origen del ritual del macho cabrío emisario hebreo, debe hacer reconsiderar la doctrina cristiana de la expiación. ${ }^{2}$ La declaración de Bremmer infiere algunos aspectos puntuales: (1) ambos rituales tienen el mismo presupuesto socio-religioso, (2) las similitudes son su absoluto y (3) el ritual hebreo fue asimilado y adaptado. Es evidente que para Bremmer es difícil hablar de diferencias, a su percepción la evidencia es tan contundente que le resulta ver lo contrario. Sin embargo, a pesar de sus similitudes, existen diferencias sustanciales que se deben considerar respecto al tipo de práctica y presuposición. ${ }^{3}$ Un

2003), 161; James Pritchard, Ancient Near East Text Relating to the Old Testament (New Jersey: Princeton University Press, 1969), 161-163, en adelante ANET.

${ }^{2} J a n$ N. Bremmer, Greek Religion and Culture, the Bible, and the Ancient Near East (Leiden, Boston: Brill, 2008), 169.

${ }^{3}$ Ida Zatelli, "The Origin of the Biblical," Vetus Testamentum 98:2 (1998) 262-263. cf. Ángel M. Rodríguez, "Paralelismos del Antiguo Cercano Oriente y la Biblia relacionados y el asunto de la Revelación e inspiración", en Theologika 17:1 (2002) 35. 
problema que se encuentra de fondo, y es el método de aproximación. ${ }^{4}$ Sabemos que el mayor desafío es la evaluación de estos paralelos sin la consideración del texto revelado. Y esto nos hace urgir de un método determinado. Por otro lado, existen según Ringgren y Vriezen algunos elementos que deben ser considerados en torno a la problemática, y son: (1) conocer el carácter respectivo de cada religión, ${ }^{5}(2)$ comprender que Israel compartía de muchas maneras la cultura del

${ }^{4}$ Una lectura de las siguientes propuestas nos muestra que comúnmente las presuposiciones metodológicas del que escribe les permite un tipo de veredicto. William W. Hallo, James C. Moyer, and Leo G. Perdue, eds., Scripture in Context II: More Essays on the Comparative Method (Winona Lake, IN: Eisenbrauns, 1983), 39. El autor sugiere que el ritual pudo ser asimilado durante el Neo-Imperio Hitita. El autor trata de hacer una evaluación diacrónica al comparar los rituales. Vease también, Zatelli, “The Origin of the Biblical", Vetus Testamentum 98:2, 254-263. Para el autor el origen del ritual pudo estar asociado culturalmente con Ebla. Aunque el autor hace una evaluación del texto de Ebla, considera que Israel fue impactado socialmente. Véase, A. E. Cundal, The Zondervan Pictorial Encyclopedia of the Bible (Grand Rapids, MI: Zondervan Pubishing House, 1975), 1:426-427. Alude que los críticos han contemplado que los textos hebreos incorporaron prácticas y conceptos paganos siendo avalados por descubrimientos arqueológicos ugaríticos y babilónicos. Véase, Charles Lee Feinberg, "The Scapegoat of Leviticus Sixteen", Bibliotheca sacra 460:115 (1958) 320-333. Para Feinberg el ritual encuentra su origen en la cultura cananea, donde un hombre era tomado como "chivo expiatorio". Cf. Gerhard F. Hasel, "The Sanctuary and the Atonement II; Biblical, Historical, and Theological Studies", en The Sanctuary and the Atonement; Biblical, Historical, and Theological Studies, ed. Arnold V. Wallenkampf and W. Richard Lesher (Washington DC: The Review and Herald Publishing Association, 1981), 115-127.

${ }^{5}$ Helmer Ringgren, "Israel's Place Among the Religions of the Ancient Near East", en Supplements to Vetus Testamentum 29 (1972) 1. 
$\mathrm{ACO}^{6}$ y (3) que sin embargo era una entidad independiente. ${ }^{7}$ Respecto al último punto, la evidencia interna del texto hebreo atestigua con un promedio de 433 textos, que Israel es una nación de características únicas. ${ }^{8}$

\section{El macho cabrío para Azazel [MCA] en Levítico 16}

\section{El contexto}

La participación del MCA se daba solo una vez por año y era dentro del ritual del Yom Kippur. ${ }^{9}$ Ross sugiere que era una ceremonia celebrada siempre el diez de Tishri, ${ }^{10}$ entre septiembre y octubre de nuestro calendario $^{11}$ y correspondiente a otoño. ${ }^{12}$ El Yom Kippur puede

${ }^{6} \mathrm{Th}$. C. Vriezen, "The Study of the OT and the History of Religion", Supplements to Vetus Testamentum 17 (1969) 14-15.

${ }^{7}$ Rodríguez, "Paralelismos", 15-16, véase también Peter Machinist, "The Question of Distinctiveness in Ancient Israel," en Essential Papers on Israel and the Ancient Near East, ed. Frederick E Greenspahn (New York: New York University Press, 1991), 425-426.

${ }^{8}$ Ibíd.

${ }^{9}$ Frank Gorman, The Ideology of Ritual; Space, Time and Status in the Priestly Theology, JOSTsup 91 (Sheffield: JSOT Press, 1990), 61. Para el autor, la práctica del ritual del Yom Kippur producía un cambio del caos al orden. Este también implicaba reorganización y restauración, de alcance cósmico, social, cultural y religioso

${ }^{10}$ Allen P. Ross, Holiness to the Lord: A Guide to the Exposition of the Book of Leviticus (Grand Rapids, MI: Baker Academic, 2002), 321.

${ }^{11}$ Harrison, TOTC, 3:174.

${ }^{12}$ Levine, Leviticus, 3:109. 
ser apreciado dimensionalmente de forma vertical Dioshombre/Dios-pueblo y horizontal desde una perspectiva social hombre-hombre y santuario-hombre. Durante la ceremonia se vislumbraban dos procesos bien definidos: la purificación del santuario y la participación del macho cabrío para Azazel, como parte del proceso de eliminación ${ }^{13}$ el cual ha sido vinculado ampliamente con חטאר y generando una discusión que aún sigue en el tapete. ${ }^{14}$ Por último, el texto de Lev 16:30 nos remite al quid del evento, los pecados habían sido acumulados en el santuario durante todo el año, y ahora debían ser eliminados. ${ }^{15}$

${ }^{13}$ Ángel Manuel Rodríguez, Substitution in the Hebrew Cultus, Andrews University Seminary Doctoral Dissertation 3 (Berrien Springs, MI: Andrews University Press, 1982), 113.

${ }^{14}$ Véase, Jacob Milgrom, Leviticus 1-16, vol. 3, Anchor Bible (Garden City, NY: Doubleday, 1991), 1040-1044. El autor identifica la función del macho cabrío por Azazel como la de un recipiente que recibe los pecados del pueblo; Baruch A Levine, Leviticus: The Traditional Hebrew Text with the New JPS Translation, vol. 3, JPS (Leiden, Boston: Jewish Publication Society, 1989), 100, 103. El autor sostiene la complejidad del uso del término כפר "expiar" en el v. 10, y la necesaria relación que este guarda con el uso de la sangre; véase Lee Feinberg, “The Scapegoat of Leviticus Sixteen", 322. Él argumenta respecto a los dos machos cabríos como un solo cf. véase, Roy E. Gane, "Schedules for Deities: Macrostructure Of Israelite, Babylonian, And Hittite Sancta Purification Days," Andrews University Seminary Studies 36: 2 (1998) 233. Él afirma que la función del macho cabrío para Azazel removía las faltas morales de los hijos de Israel, véase también Corinna Körting, "Theology of Atonement in the Feast Calendar of the Temple Scroll", Scandinavian Journal of the Old Testament 18:2 (2004) 241. El חטאת mencionado en Lv 16, encierra una concepción e impacto doble del pecado de los hijos de Israel, describiendo la contaminación del santuario y cómo el macho cabrío por Azazel erradicaba los pecados.

${ }^{15}$ Véase, Roy Gane, Altar Call (Berrien Springs, MI: Diadem, 1999), 


\section{Desarrollo ritual}

Una lectura cuidadosa del texto atendiendo su estructura literaria, permite al lector visualizar que el rito del MCA se encuentra insertado de forma natural al ritual anual. ${ }^{16} \mathrm{El}$ v. 5 describe que la ofrenda del pueblo comprendía 2 machos cabríos y un becerro. El MCA aparece en escena dos veces durante el ritual: La primera vez que ocurre en vv. 7-8, y la segunda en 21-22, 26. La función del MCA es definida mediante el rito de suerte descrita en los v. 8. Esto permite afirmar que antes de este paso ninguno de los machos cabríos contaba con una función específica. ${ }^{17}$

203-209. La discusión a este nivel es si la presencia del macho cabrío para Azazel cumplía más que una simple participación, o si su participación además de ser necesaria cumplía un rol tipológico.

${ }^{16}$ Para una discusión respecto a la complejidad de la estructura de Levítico 16, véase: Ángel M. Rodríguez, “Leviticus 16: It's Literary Structure", Andrews University Seminary Studies 32:2 (1996) 269-286. En su análisis literario de Levítico 16, el autor ha observado que estos paralelos pueden ser: antitético, sinónimo y aun sintético; véase, Derek Tidball, Levítico (Barcelona: Publicaciones Andamio, 2009), 246; John E. Hartley, Leviticus, ed. David A. Hubbard and Glenn W. Barker, vol. 4, Word Biblical Commentary (Dallas, TX: Word Books, 1992), 224, 225; Gordon J. Wenham, The Book of Leviticus, vol. 3, The New International Commentary on the Old Testament (Grand Rapids, MI: Wm. B. Eerdmans Publishing, 1979), 228; Carl Friedrich Keil y Franz Delitzsch, Commentary on the Old Testament, vol. 1 (Grand Rapids, MI: Wm. B. Eerdmans Publishing, 1975), 394-406.

${ }^{17}$ Véase, Milgrom, $A B, 3: 1063$. De acuerdo al autor existe una necesidad de incluir los versos 7-10, puesto que esto permite determinar un orden entre el v. 6, y el v. 11, respecto a la lectura del sacrificio por el sacerdocio Aarónico; véase también, Wenham, NICOT, 3:231-232. Refiere que los ver- 
No hay participación directa del MCA hasta después de haber terminado el proceso de purificación del santuario. Comprendiendo que su participación es claramente otra.

Parte de la discusión ha recaído en la relación que tiene el MCA con los términos חטאת en el v. 5, 21 ע חטיו לכפר en el v. 10. Respecto al uso de חטאת en el v. 5, debe tenerse presente que no hace referencia específica a uno de los machos cabríos, sino a ambos. Por otro lado el uso de חטאת en el v. 21, pasa a describir el agente contaminante, que se conecta con la confesión y transferencia al macho cabrío vivo, ${ }^{18}$ por lo que el macho cabrío para Azazel no debe ser tomado como una ofrenda מטארת עלכו el uso de לכפר עליו, es fuertemente discutido por Milgrom, quien propone que la preposición על לליו debe ser traducida "sobre" en vista que el macho cabrío vivo actúa como un objeto inanimado y por lo tanto la frase לכפר עליו, "expiar sobre él", indica que la expiación toma lugar sobre él. ${ }^{20}$ Este argumento se ajusta al orden sintáctico, pero provee una vislumbre pálida del rol simbólico del ritual. No obstante, una consideración mayor de la función del verbo כפר puede ser vista en el Tárgum Pseudo Jonatan ${ }^{21}$ el

sículos subsiguientes en la prescripción del ritual omiten el acto de echar suertes por ser ahora innecesario, puesto que ya debía haber sido realizado, como lo refieren los vv. 7-8; véase Ross, Holiness, 318.

${ }^{18}$ Roy E. Gane, "Temple and Sacrifice", Journal of the Adventist Theological Society 10:1-2 (1999) 363.

${ }^{19}$ Nobuyoshi Kiuchi, The Purification Offering in the Priestly Literature, Its Meaning and Functión, JSOTsup 56 (Sheffield: JSOT Press, 1987), 145.

${ }^{20}$ Milgrom, $A B$, 3:1023; véase también, Gorman, The Ideology of Ritual, 95.

${ }^{21} \mathrm{El}$ tárgum resulta ser una interpretación de la lectura de la Torá, y 
cual recomienda que לכפר עליו pueda ser entendido como el acto de "expiar cerca a este", 22 considerando el acto expiatorio del macho cabrío para Yahvé en proximidad al macho cabrío para Azazel.

Otra parte sobresaliente es la imposición de manos en los vv. 21-22. La imposición de manos aquí es un acto simbólico de transferencia ${ }^{23}$ y el texto indica la naturaleza de esos elementos. Así los “iniquidades”,

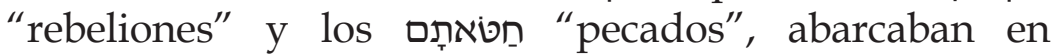
combinación todo tipo de faltas de dimensión moral de los hijos de Israel. En suma, cuando el macho cabrío vivo es enviado al desierto actúa como un vehículo de remolque que se va llevando todo el pecado de Israel. El rito describe simbólicamente un acto judicial. En tal sentido, el macho cabrío estaría cargando y afrontando la responsabilidad por las culpas del pueblo de los hijos de Israel. De esta manera, tipológicamente es enviado a un exilio como

su percepción en la lectura del texto puede ayudarnos a comprender mejor el pensamiento semita. Una lectura al Targum Pseudo Jonatan de la frase " " לכפרא על סורחנות עמא בית ישראל "para expiar sobre él los pecados de los hijos de Israel" indica que la preposición על ליתל של refiere al pueblo y no al macho cabrío, entendiéndose que el acto expiatorio fue hecho por el pueblo, y en este caso el único sacrificio hecho en favor del pueblo fue el del macho cabrío por Yahvé.

${ }^{22}$ Alberto R Treiyer, The Day of Atonement and the Heavenly Judgment: From the Pentateuch to Revelation (Siloam Springs, AR: Creation Enterprises International, 1992). 45; véase también Levine, Leviticus, 3:103.

${ }^{23}$ Rodríguez, Substitution, 137-138, véase M. L. Andreasen, El Santuario y su Servicio (Buenos Aires: Asociación Casa Editora Sudamericana, 1979), 155-156. El autor contempla que el Yom Kippur de Lev 16, refleja el juicio en el final de los tiempos donde después de realizarse el resarcimiento de los justos Satanás será castigado. 
parte de su juicio, encontrando posteriormente la muerte. ${ }^{24}$ Muerte que repercutiría en la restauración del pueblo de Israel en su relación con Dios, al ver la eliminación total del pecado (Mal 4:1). ${ }^{25}$

\section{Consideraciones}

El ritual del MCA, involucraba aspectos bien definidos: (1) no era una ofrenda expiatoria, (2) este participaba solo una vez al año, (3) su participación se ubicaba inmediatamente después de la purificación del santuario, (4) su función era únicamente como vehículo de transporte y (5) su rol cumplía también una función tipológica (¿judicial?).

\section{El ritual de Puliša (CTH 407)}

\section{Contexto ritual}

El ritual hitita por la plaga o también ritual de eliminación, es un documento prescriptivo que evidencia motivo, personajes, elementos e instrucciones. Puliša es recordado en un sammeltafel, un grupo de rituales alusi-

${ }^{24}$ Del mismo modo la Escritura ya en un juicio escatológico muestra al mismo Satanás, recibiendo juicio (Apo 19:20) como se hacía con el macho cabrío por Azazel al ser colocado en la presencia del Señor y recibir las culpas de los hijos de Israel para luego ser enviado a un lugar desértico. Esta figura es también desarrollada en Apo 20:1-3 con Satanás al ser atado y arrojado por espacio de mil años. Esta misma imagen se repetía constantemente en el ritual del día de la expiación en el santuario hebreo en los vv. 10, 21 (2 veces). Donde perdería la vida (Lev 16:21; Apo 20:7-9).

${ }^{25}$ Gorman, The Ideology of Ritual, 98. 
vos a la práctica del chivo expiatorio. Es importante considerar este último término puesto que el término expiatorio genera por sí mismo una serie de implicaciones. El ritual de Puliša fue establecido para contrarrestar un tipo de plaga que asolaba la ciudad. Dentro de la cosmovisión hitita, la plaga o peste había sido enviada por alguna deidad enemiga dentro de un contexto de guerra. El texto alude que el proceso ritual comprende la inclusión de encantamientos, personas y animales que cumplen la función de ofrenda sustitutoria y a su vez o similar a la del chivo expiatorio.

\section{Desarrollo ritual}

El ritual de Puliša está compuesto de siete colofones [§]. El §1 describe el contexto de aplicación. Nótese que este contexto no expresa tiempo específico. El §2 y 3 indican el tipo de participantes, dos prisioneros de la nación enemiga: un hombre y una mujer. La mayor parte del ritual se concentra en estos colofones describiendo el acto sustitutorio por medio de la expresión "hombre sustituto" (LÚ PU-HI-ŠU) ${ }^{26}$ y la utilización de los prisioneros como chivos expiatorios. ${ }^{27}$ Es importante notar que la elección de un varón y una mujer como ofrenda, demuestra que los mismos hititas desconocían

${ }^{26}$ David Pearson Wright, "The Disposal of Impurity in the Priesly Wrytings of the Bible with Reference to Similar Phenomena in Hittite and Mesopotamian Cultures" (Doctoral Degree Conferred, Berkeley: University of California, 1984), 46.

${ }^{27}$ Ibíd., 45. 
la naturaleza de la deidad agresora. ${ }^{28}$ Aún más, esto cuestiona la cualidad omnisciente de sus deidades. Por otro lado el colofón $\S 4$, indica el tipo de ofrenda, un toro y una oveja, lo que para Wright es un indicador de congruencia sexual, tal como se apreció en el colofón anterior. ${ }^{29}$ A estos se les colocaría un pendiente en la oreja con lanas de color rojo, amarillo, verde, blanco y negro. Después el rey se colocaría delante del toro y recitaría un conjuro. Este procedimiento cumplía tres funciones: (1) los adornos de colores representaban la concretización del mal que aquejaba al rey o la nación, siendo con el rito transferidos del rey al animal, ${ }^{30}(2)$ no obstante, tales adornos también servían de atractivo para la deidad ${ }^{31}$ para (3) cumplir la función de ofrenda. ${ }^{32}$ Puede notarse con el envío de la ofrenda que el objetivo principal era erradicar la plaga y hacer que la deidad se volviera en amistad con la nación. ${ }^{33} \mathrm{El} \S 5$,

${ }^{28} \mathrm{La}$ orientación sexual de la ofrenda indica además de la naturaleza politeísta del pueblo, que no estaban seguros que deidad los había atacado. Trevor Bryce, Life and Society in the Hittite World (Oxford; New York: Oxford University Press, 2002), 135, véase también, Wright, "The Disposal”, 47.

${ }^{29}$ Ibíd., 46, 47.

${ }^{30}$ Ibíd., 47.

${ }^{31}$ Ibíd.

${ }^{32}$ Bryce, Life and Society in the Hittite World, 190. El autor refiere que las recitaciones formaban parte de las celebraciones a los dioses hititas, demostrando hospitalidad a los dioses y entretenimiento.

${ }^{33}$ Hallo and Younger, Canonical Compositions, 1:161. Esto se evidencia en la parte final de colofón 4, por medio de la frase "Vuelve en amistad con el rey, los príncipes, los señores, el ejército y la tierra de Hatti...". 
describe lo mismo delante de la oveja en caso de una deidad femenina. Por último, los $\S$ 6-7 describen como el buey corre delante de los prisioneros. Esto significa, que los participantes sustitutorios adquieren en estos colofones un cambio de rol, actuando ahora, como vehículos de carga. ${ }^{34}$

\section{Consideraciones}

Se pueden extraer algunos elementos bien definidos a lo largo del proceso: (1) el modus operandi es por causa de una peste buscando el bienestar del rey y de la población, ${ }^{35}(2)$ el ritual no establece una fecha o día específico solo se ejecuta en momentos requeridos, (3) el "chivo expiatorio" puede ser una persona (hombre o mujer, a veces los dos o más), oveja (en el caso de una deidad femenina) o un toro (en el caso de una deidad masculina) o macho cabrío. ${ }^{36}$ Dentro de este punto (4) el rey, así como otros participantes, cumplen un rol sacerdotal ${ }^{37}$ como "ejecutor del ritual", (5) el espacio ritual no es definido en el texto, solo se indica que el ejército debe alejarse de la ciudad [colofón 2], (6) el

${ }^{34}$ Wright, "The Disposal", 47.

${ }^{35}$ Hallo y Younger, Canonical Compositions, 1:161-2.

${ }^{36}$ David P. Clark, Germs, Genes \& Civilization How Epidemics Shaped Who We Are Today (New Jersey: FT Press, 2010), 176.

${ }^{37}$ Bryce, Life and Society in the Hittite World, 187. Según el autor el sacerdote era un oficiante común en las ceremonias en pro de las deidades, donde, se mostraba sumiso y como siervo. Esta puede ser la misma función del rey en el ritual de Puliša, el rey espera una reacción favorable por parte de la deidad. 
uso de la magia está presente, por medio del acto de recitación, desarrollando transferencia, (7) el "chivo expiatorio" era enviado a la deidad del país enemigo ${ }^{38}$ a manera de ofrenda, en un intento de ganar su amis$\operatorname{tad}^{39}$ y (7) a lo largo del ritual el elemento de transferencia no se ve asociado con asuntos morales, sino solo con un virus infeccioso. ${ }^{40}$

\section{El ritual de Puliša y el MCA, el punto de desencuentro}

La búsqueda de ciertos paralelos entre los rituales hebreos e hititas, ha llamado la atención de algunas escuelas. ${ }^{41}$ La evidencia textual demuestra que tanto en el ritual hebreo como el hitita sí es posible apreciar similitudes, las cuales deben ser evaluadas cuidadosamente dentro de su contexto de acción. ${ }^{42}$

${ }^{38}$ Bremmer, Greek Religion and Culture, 35-36.

${ }^{39}$ Bryce, Life and Society in the Hittite World, 134.

${ }^{40} \mathrm{En}$ el ritual hebreo el elemento de transferencia eran todos los pecados y las impurezas causadas por el pueblo de Israel, los que a su vez eran aludidos por la combinación פטאת y עשון

${ }^{41}$ Calum M. Carmichael, Illuminating Leviticus A Study of Its Laws and Institutions in the Light of Biblical Narrative (Baltimore, MD: The Johns Hopkins University Press, 2006), 40; Rodríguez, Paralelismos, 29-38; véase también, J. Dyneley Prince, "The Assyro-Babylonian Scapegoat Controversy", The American Journal of Semitic Languages and Literatures 20:3 (1904) 173-181.

${ }^{42}$ Yanowitz, “Do Jews Make Good Protestants?" 29. 


\section{Similitudes}

\section{Transferencia y eliminación}

Estos dos elementos son fuertemente evidenciados dentro de ambas prácticas rituales. En el caso del ritual de Puliša el $\S 2$ nos provee la evidencia:

§ 2 A medida que se marchaban lejos de la frontera de la tierra de los enemigos, toman un preso y una mujer de la tierra (enemiga)... Se quita la ropa de su cuerpo. La pone en el hombre. Pero a la mujer ropa de una mujer. Para el hombre el rey dice... de la siguiente manera: "si un dios masculino de la tierra enemiga, para el Yo doy un hombre adornado como sustituto. Este es grande con respecto a la cabeza, este es grande con respecto a su corazón, y éste es grande con respecto a su miembro. Tú dios masculino, sé apaciguado con este hombre adornado. Vuelve en amistad con el rey, [los señores], el ejército, y la tierra de Hatti. [...] así deje a este prisionero llevar la plaga y la transporte de nuevo a tierra enemiga. ${ }^{43}$

Un sentido de transferencia se puede ver en el ritual, y los vestidos simbolizan el mal que amenaza la vida del rey, exigiendo su participación real. ${ }^{44} \mathrm{Al}$ intercambiar sus vestidos, el rey está adhiriendo el mal

${ }^{43}$ Hallo and Younger, Canonical Compositions, 1:161.

${ }^{44}$ Billie Jean Collins, "Hittite Religion and the West", 57. 
al "chivo expiatorio" (prisionero) ${ }^{45}$ o nakkussit ${ }^{46}$, quien ahora cumple la función de sustituto. ${ }^{47}$ Esta práctica ha sido considerada como análoga al acto de transferencia y eliminación del macho cabrío para Azazel en Lev 16:21, aunque con algunas excepciones.

Existe un contraste en medio de todo el ritual del macho cabrío para Azazel en el culto hebreo. Este no es usado para erradicar alguna plaga como lo expresa el ritual hitita. En Levítico 16 esto no se registra. Los vv. 16 y 19 hacen referencia explícita al elemento de expulsión, את־כל־ונת בני ישראל ואת־כל־פעיהם לכל־טאתם "todas las iniquidades de los hijos de Israel, todas sus rebeliones por todos sus pecados". El texto señala claramente que el elemento de remoción son las iniquidades, rebeliones y los pecados en su totalidad. Estos son generados por los hijos de Israel, y puestos sobre el MCA para ser enviado al desierto a morir y no como ofrenda a una deidad o ser demoniaco. ${ }^{48}$ El MCA no puede ser ofrenda, puesto que el acto de transferencia lo convierte en agente de impureza. Esto se cristaliza en el v. 26, donde el "hombre designado" איש עתי, debía participar de un estricto ritual de ablución (v. 26). Se puede concluir esta parte,

${ }^{45}$ Yanowitz, "Do Jews make good protestants?", 30.

${ }^{46} \mathrm{El}$ término empleado para señalar propiamente la función del chivo expiatorio en la literatura hitita, es nakkussi. Su mención se ha dado en rituales de la ciudad de Samuha de la tierra de Upper, véase Charles Allen Burney, Historical Dictionary of the Hittites (Lanham, MD: Scarecrow Press, 2004), 183.

${ }^{47}$ Yanowitz, "Do Jews make good protestants?", 30.

${ }^{48}$ Pritchard, ANET, 347; Hallo y Younger, Canonical Compositions, 1:161-163. 
indicando que aunque hay una función de transferencia y eliminación en ambos rituales, estos difieren en propósito, procedimiento, elemento de eliminación y el origen del elemento de expulsión.

\section{Diferencias}

Los actos que hacen ampliamente diferente a estos rituales son los conceptos de: 1) sustitución, 2) pecado, 3) moral, 4) apaciguamiento y 5) magia.

\section{Sustitución}

El acto sustitutivo era ampliamente practicado en el culto hebreo e hitita. Sin embargo, la idea de sustitución aunque muy común en el culto hebreo, no está presente en el MCA y esto genera una diferencia entre ellos. ${ }^{49} \mathrm{El}$ chivo expiatorio como sustituto había de tomar el lugar del afectado, tal cual se observa en el ritual de Puliša:

Para el hombre el rey dice de la siguiente manera... "Si algún dios (masculino) de la tierra enemiga ha provocado esta plaga, por causa de él yo justamente entrego a un hombre adornado como un sustituto". ${ }^{50}$

La razón básica para el acto sustitutorio era que el prisionero tomase el lugar del rey y este sea restituido a su estado natural, y la amenaza de destrucción sea devuelta a

${ }^{49}$ Rodríguez, Substitution, 54.

${ }^{50}$ Hallo and Younger, Canonical Compositions, 1:161. 
su originador. ${ }^{51}$ No obstante, en el culto hebreo el concepto de sustitución era mucho más amplio, implicando perdón y restauración. Comúnmente, el pecador transferiría a la ofrenda o víctima sacrificial su pecado, el cual moría en su lugar satisfaciendo las demandas de la ley divina. ${ }^{52}$ Este acto expiaba los pecados del oferente encontrando perdón (Lev 4:20, 26, 31; 5:6-18). En el culto hebreo la ofrenda sustitutoria se distinguía por tres aspectos muy importantes: (1) El sacrificio de la ofrenda, (2) el uso de la sangre y (3) la disposición de la carne..$^{53}$ Sin embargo, durante el ritual del día de la expiación el macho cabrío para Azazel no es objeto de ninguno de estos procedimientos imposibilitándolo como sustituto. ${ }^{54}$

\section{El concepto de pecado}

Dentro de las prácticas hititas, el concepto de pecado está ausente. Sin embargo, en el texto bíblico los

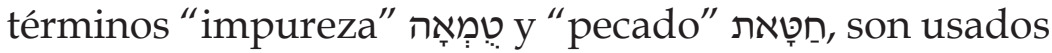
intercambiablemente al instante de indicar el elemento de expulsión o purificación(Lev 17:15-16)..$^{55}$ Así la consideración que tenían los hebreos de pecado estaba fuertemente asociada

${ }^{51}$ Gary Beckman, "The Religion of the Hittites," The Biblical Archaeologist 52:2-3 (1989):103, 106.

${ }^{52}$ Rodríguez, Sacrificial Substitution, 134.

${ }^{53}$ Roland de Vaux, Ancient Israel: Its Life and Institutions (Grand Rapids, MI: Wm. B. Eerdmans Publishing, 1997), 419.

${ }^{54}$ Ross, Holiness, 321.

${ }^{55}$ S. David Sperling, "Wright's 'The Disposal of Impurity'", The Jewish Quarterly Review 80:1-2 (1989): 195. 
a la idea de impureza o de un agente contaminante (Lev 16:16). No obstante, al igual que en los hititas atentaba contra la vida del ofensor. ${ }^{56}$ Contrariamente, los hititas incurrían en prácticas de corrupción moral, pues sus dioses comúnmente exigían ofrendas, y hasta cierto punto dependían de un tipo de ofrenda que involucraba muerte y ritos sexuales. ${ }^{57}$ De esta manera el concepto de pecado como agente contaminante que debía ser expulsado por medio de un chivo expiatorio, era único en el culto hebreo. ${ }^{58}$

\section{Moral}

La moral del pueblo hebreo estaba asociada a sus leyes. El sistema legislativo hebreo tenía como prioridad velar por la vida e integridad del ser humano sin distinción, funcionando comúnmente, como un cerco de protección frente a las prácticas de los pueblos paganos (Deu 7:1-6). Estas leyes involucraban tanto a nativos como extranjeros que se encontraban morando en medio de la nación hebrea (Lev 19:30-33; 24:16). La ley de Dios actuaba como un reflejo de su carácter y su justicia (Lev 11:44), por lo que estas leyes, actuaban como reguladoras en materia de santidad conservando prácticas

${ }^{56} \mathrm{El}$ concepto de pecado como una fuente generadora de impureza señalada en Lev 16:16, es también considerada en Isa 6:5-7, donde el profeta con-

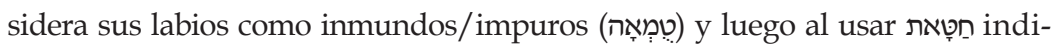
cando que el pecado ha sido limpiado de ellos. Así, el uso intercambiable

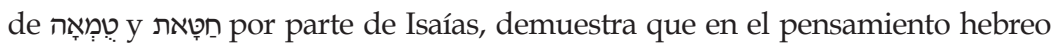
el referir algo inmundo en una persona era sinónimo de pecado. Este mismo tratamiento es visto en textos posteriores como Eze 14:11, 37:23; 36:25; Sal 51:4.

${ }^{57}$ Bryce, Life and Society in the Hittite World, 146.

${ }^{58}$ Sperling, "The Disposal", 197; Burney, "Magic", HDH,184. 
morales que alcanzaban un impacto social (Lev 24:16). ${ }^{59} \mathrm{La}$ evidencia textual en los rituales hititas, exhibe contrariamente cómo el ser humano es rebajado al nivel de un instrumento o un objeto, al punto de disponer de él como bien les pareciese al rey, pueblo y deidad. Los rituales hititas hacían uso de las personas sin considerar su valor como creación divina. Mientras que el único que poseía un estatus mayor, era el rey quien representaba a los dioses. Y bajo ese estatus, él mismo, se confería la autoridad de vejar a un hombre o mujer.

\section{Apaciguamiento}

Un tercer aspecto en el que ambos rituales discrepan es la idea de que el "chivo expiatorio hitita" y el macho cabrío para Azazel, comparten la idea de aplacar la ira de un dios airado del desierto. Este argumento está en contra de la profesión monoteísta del pueblo hebreo, puesto que sus mismas ordenanzas prohibían la presentación de ofrenda a dioses/demonios que supuestamente vivían en el desierto (Lev 17:7; Deu 32:17; Isa 13:21; 34:14). ${ }^{60}$

\section{Magia}

La magia y el espiritismo eran bastante comunes entre los pueblos del ACO y fuertemente prohibidos por Dios a la nación hebrea (Lev 19:26, 31; 20:27; Deu 18:1014). Se sabe que los rituales hititas estaban constituidos de conjuros donde se fabricaban hoyos en la tierra para

${ }^{59}$ Hartley, Leviticus, 4:247-9.

${ }^{60}$ Henrike Frey-Anthes, "Concepts of 'Demons' in Ancient Israel", Die Welt des Orients, 38 (2008) 43; Toy, "Evil Spirits in the Bible", 18. 
comunicarse con los muertos. La terminología usada para este fin, se aprecia en la palabra $a-a-b i{ }^{61}$ Hoffner asegura que una comparación de $a-a-b i$ con la palabra hebrea heb. אוֹב 'ôb "espíritu de muertos", exhibe prácticas sin lugar a duda de necromancia. Así también, durante los rituales hititas por la plaga un "mago", "hechicero" o "médico" indicaba dos procesos cargados de magia: (1) las palabras a manera de conjuro recitadas por el rey delante del "chivo expiatorio" (animal o persona) que lo constituía como sustituto y (2) el uso de un adorno de lana de colores variados (amarillo, rojo, negro, verde) el cual servía como medio para llamar la atención y traer en amistad a la deidad enfurecida. El uso de estos términos y su comparación puede darnos una noción más clara que la práctica ritual hitita abundaba en magia y espiritismo. ${ }^{62}$

Una visualización del proceso desarrollado entre el ritual hebreo e hitita puede sintetizarse de la siguiente manera:

Concepción hitita del ritual Puliša o por la plaga

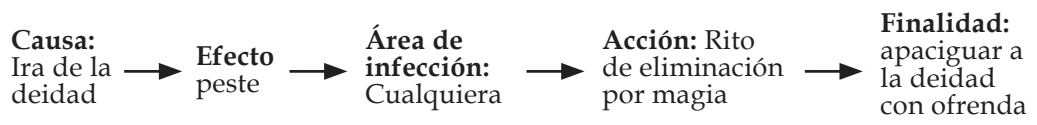

Concepción hebrea del ritual Yom Kippur

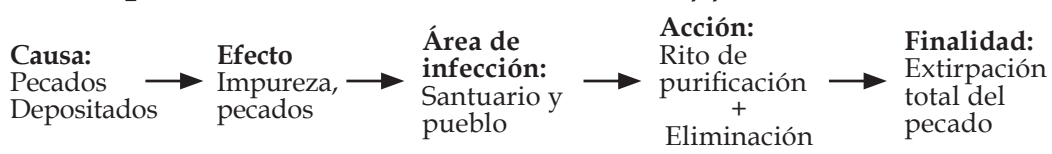

${ }^{61}$ Hoffner, 151.

${ }^{62} \mathrm{Ibíd}$. 
Dentro de las diferencias entre los paralelos hebreohititas, resulta interesante notar que en el ritual bíblico la remoción ocurra solo después de la purificación o la curación mientras que en Mesopotamia el ritual hitita no expresa una eliminación de la enfermedad o sospecha de mal. En el caso del macho cabrío emisario en el ceremonial hebreo, los pecados confesados de la comunidad sobre él son transferidos por el sumo sacerdote. Sin embargo, este ritual no tiene nada que ver con los males particulares que se derivan de los pecados de la persona. ${ }^{63}$

Hay algunos puntos en esta dirección: (1) así, si Dios al instituir sus leyes hace que se generen o evidencien los pecados por ignorancia, él también provee la cura o expiación (perdón)/ solución, (2) el uso constante del verbo en piel כִֶּ "expiar" para la expiación de los pecados describe la naturaleza de la solución para el sacrilegio contra

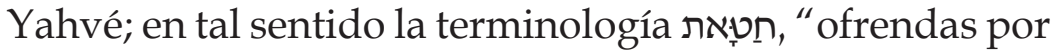

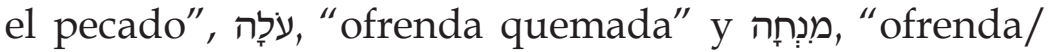
regalo", cumplen un rol expiatorio, cubriendo los pecados inadvertidos de una persona, guardando directa relación con la ley moral de Dios ya que ocurre reconciliación entre las partes divina y humana. ${ }^{64}$ Por otro lado, la práctica hitita comprendía simplemente un accionar como señal de protección frente al mal causado por un espíritu malhumorado. ${ }^{65}$

Por último, el ritual bíblico se concentra en la impureza que se encuentra en el pueblo y el santuario.

${ }^{63}$ Augustine Pagolu, The Religion of the Patriarchs, vol. 227, JSOTsup (Sheffield: JSOT Press, 1998), 228.

${ }^{64} I b i ́ d ., 229$.

${ }^{65}$ Ibíd. 
Mientras que en los hititas, el mal posee varias manifestaciones, varios tipos de enfermedad, miedo, desgracia, anomalías, derrota y muerte ipero nada de impurezas! Aun así, si fuese mencionado el concepto de impureza, comúnmente, este no es el objeto de los rituales hititas. En cambio, la seguridad del traslado de las impurezas relacionadas con el pecado son llevadas fuera del campamento por el macho cabrío para Azazel es la más grande contribución que el ritual del Yom Kippur concede. ${ }^{66}$

\section{Conclusiones}

Este estudio ha mostrado que a pesar de las similitudes existen diferencias importantes entre la práctica ritual de Puliša y el macho cabrío para Azazel en el Yom Kippur del culto hebreo, el resultado es sumamente contrastante al considerar las dimensiones rituales de cada uno.

Un aspecto muy resaltante en los rituales hititas, son los esfuerzos por reprimir la ira de la deidad enemiga, asociado comúnmente con dar algún tipo de pago para lograr el objetivo. Por otro lado, en el culto hebreo el carácter de Dios además de comprender la inminencia de su justicia contra el pecado, encontraba íntima conexión con su misericordia (Éxo 34:6). No obstante, la misericordia es evidentemente mayor que su ira (Miq 7:18).

En los pueblos hititas la sustitución era un recurso usado para erradicar la plaga donde los "chivos expiatorios" eran siempre personas marginales, como prisioneros de guerra. Cabe resaltar que estos podían remplazar tanto al rey, al pueblo o alguna persona natural. En este

${ }^{66}$ Ibíd. 
proceso también se incluían la imposición de manos, confesiones audibles o conjuros. Asimismo, se ven inmersos casi siempre los mismos elementos y procedimientos: un prisionero, una oveja, un carnero, un macho cabrío, la imposición de manos. ${ }^{67}$ En el culto hebreo, la sustitución implicaba una solución no venida de un médico o sacerdote, sino por parte de Dios. La ofrenda tenía requerimientos que debían seguirse, ya que esta debía ser perfecta para cumplir su rol simbólico. Sin embargo, en el ritual hebreo el macho cabrío emisario no es una ofrenda sustitutiva, este era simplemente un vehículo de remoción.

La eliminación es un punto en común entre los rituales del ACO y el hebreo. La maldad, peste y contaminación debía ser dirigida fuera y lejos del campamento. En la práctica hebrea el macho cabrío emisario era enviado al desierto, llevando sobre sí la contaminación de la nación. En el pueblo hitita el sustituto era enviado al país enemigo en busca de perdón y amistad. Ambos simbolismos tenían como fin señalar el regreso del mal a su lugar de origen.

Además, como puede notarse, el uso de un lenguaje religioso así como legal era muy familiar en el ACO, aunque con un significado propio para Israel. Por ello, es imprescindible un estudio del texto bíblico antes de sumergirse en paralelos probables. ${ }^{68}$

Finalmente, al momento de considerar paralelismos entre la Biblia y los pueblos vecinos de Israel, se debe considerar su lectura dentro de su propio marco contextual y conceptual. Pues solo así, se logrará observar las particularidades entre cada ritual o paralelismo.

${ }^{67}$ Rodríguez, Substitution, 333.

${ }^{68}$ Rodríguez, "Paralelismos", 38. 